\title{
The Firm as an Interactor: Firms as Vehicles for Habits and Routines
}

\author{
Geoffrey M. Hodgson and Thorbjørn Knudsen
}

9 December 2003

Published in the Journal of Evolutionary Economics, 14(3), July 2004

\author{
The Business School, University of Hertfordshire, Mangrove Road, Hertford, Hertfordshire SG13 8QF, UK \\ and \\ Department of Marketing, University of Southern Denmark, Odense Campus, 5230 Odense M, Denmark \\ Address for correspondence: \\ Malting House, 1 Burton End, West Wickham, Cambridgeshire CB1 6SD, UK \\ g.m.hodgson@herts.ac.uk
}

KEY WORDS:

Firms, evolutionary economics, knowledge, habits, routines, replicator, interactor

JEL classification: B25, B52, D20, D83, L20

\begin{abstract}
This paper pursues a research agenda inspired by Richard Nelson and Sidney Winter's Evolutionary Theory of Economic Change (1982). This seminal work applied the Darwinian concepts of variation, replication and selection to the evolution of firms. It proposed a level of evolution, replication and selection at a level higher than individuals or genes, involving the replication and selection of routines and institutions. Significantly, the applicability or otherwise of these Darwinian concepts depends on precise definitions of terms such as replication and selection. The present essay builds on previous work where the concepts of replication (Godfrey-Smith, 2000; Aunger, 2002; Hodgson, 2003b) and selection (Price, 1995; Frank, 1998; Knudsen, 2002b, 2003) have been refined. We deploy the key concepts of 'replicator' and 'interactor' from the modern philosophy of biology (Hull, 1981, 1988). It is shown that while habits and routines can be regarded as replicators, there is a case for regarding firms and similarly cohesive organizations as interactors. We explore some of the implications of this result and provide an important component in the construction of a multiple-level evolutionary theory, involving replicating units at several socio-economic levels.
\end{abstract}




\title{
The Firm as an Interactor: Firms as Vehicles for Habits and Routines
}

\author{
Geoffrey M. Hodgson and Thorbjørn Knudsen
}

Empirical evidence is usually too malleable to be very decisive in conceptual revolutions. ... Initial acceptance of fundamentally new ideas leans more heavily on the increased coherence which the view brings to our general world picture.

David L. Hull (1978)

Once we see that other levels of selection are theoretically possible, we should not adopt a methodology that blinds us to their existence.

Robert N. Brandon (1996)

This essay is concerned with the application of Darwinian principles to our understanding of the nature and evolution of business firms. ${ }^{1}$ It continues in the evolutionary tradition of theoretical enquiry in social science, inspired and developed by Richard Nelson and Sidney Winter (1982), Michael Hannan and John Freeman (1989), Howard Aldrich (1999) and many others. Our focus here is on some of the deeper, conceptual issues involved in the use of evolutionary ideas in this context.

The term 'evolutionary' does not necessarily invoke Darwinism, but we take the use of Darwinian ideas within evolutionary economics seriously. This does not mean that we overlook the huge differences between the mechanisms involved in biological evolution, on the one hand, and socio-economic evolution, on the other. Neither do we believe that social phenomena can be largely explained in biological terms. Instead, we take what is now a prevailing view in the philosophy of science, that Darwinism involves a set of general principles that apply to all evolving systems involving variation, inheritance and selection. The most important service rendered by these general principles is to help explain the evolution of widespread but incredible levels of complexity in reality. However, the conceptual refinement of the core Darwinian concepts is incomplete, and much work needs to be done, particularly in their application to the social sciences. This article is a contribution to this effort.

\footnotetext{
1 Sections 1-3 of this essay make use of some material from Hodgson (2003b) and Knudsen (2002a, 2002b, 2004). The authors are very grateful to Howard E. Aldrich, Robert Aunger, Markus C. Becker, Marion Blute, Abhirup Chakrabarti, Peter Corning, David L. Hull, three anonymous referees, and the editor Uwe Cantner for help and valuable comments on earlier drafts.
} 
The first section below introduces the concept of Universal Darwinism by reviewing some of the literature on the generalised application of Darwinian principles. Nelson and Winter (1982) famously described routines as 'genes'. Accordingly, the second section considers how habits and routines can serve as replicators in socio-economic evolution. The third section considers the meaning of selection, and the selection of habits and routines. This paves the way for the fourth section, which is the crux of our argument. If routines are in some ways like genes, and are thus key 'replicators' in economic evolution, what serve as their 'vehicles' or 'interactors'? We argue that the firm is best regarded as their interactor. The application of the accepted definition of an interactor (Hull, 1988, p. 408) in this domain has the following consequence: upon the outcome of the interactions between an interactor with its environment, the fate of its constituent replicators depends.

The outcome of this argument is, first and foremost, a conceptual refinement of the approach developed by Nelson and Winter (1982), which clarifies the evolutionary elements and mechanisms involved, in the light of recent developments in the philosophical analysis and formalisation of Darwinian principles. We also hope that this is a small step in the development of a wider theory of socio-economic evolution, which can link the insights of modern evolutionary economics with the growing understanding and refinement of key evolutionary concepts such as selection and replication.

In particular, the recognition of firms (and perhaps some other institutions) as interactors, alongside the accepted interactor of the human individual, paves the way for the further development of a multiple level evolutionary theory, with interactors on both institutional and individual levels. The development of such a multi-level theory is the keystone of a nonreductionist evolutionary economics.

\section{Universal Darwinism}

A few years after the publication of Darwin's Origin of Species (1859), several scholars followed Darwin's own hints that the principles of selection, variation and inheritance may have a wider applicability than to biological organisms alone. In The Descent of Man (1871) Darwin had elaborated on this possibility. A number of early thinkers, including Walter Bagehot (1872), William James (1880), David Ritchie (1896), Charles Sanders Peirce ([1898] 1992), Thorstein Veblen (1899, 1919), and James Mark Baldwin (1909) argued that the Darwinian principles of selection apply not simply to biology but also to mental, epistemological, moral, social or even cosmic evolution. Their arguments did not involve the reduction of explanations of social phenomena to biological terms alone. In contrast, they argued that Darwinian ideas themselves had wider application, to non-biological, evolving systems. However, their efforts were largely overshadowed by the Darwinian assault on creationism.

The idea of extending the application of Darwinian principles was later revived. Karl Popper (1972) and Donald T. Campbell (1974) developed an 'evolutionary epistemology'. Campbell also argued that Darwinism contained a general theory that applied to all evolving systems. Campbell (1965, p. 24) made the point that the appropriate analogy for social evolution is not biotic evolution, but a more general processes of evolution 'for which organic evolution is but one instance'. Subsequently, Richard Lewontin (1970) also suggested that the domain of application of Darwinian theory could be broadened from biology.

Richard Dawkins (1983) later coined the term 'Universal Darwinism'. Dawkins argued that if life existed elsewhere in the universe, it would follow the Darwinian rules of variation, 
inheritance and selection. Even if there were a very different system of replication, including one that allowed the 'Lamarckian' inheritance of acquired characters, a coherent account of the evolutionary process would still require the key elements of the Darwinian theory. Even in the social context, where acquired characters might be inherited, such Lamarckism requires Darwinism to complete its explanations, and is not an alternative to it. ${ }^{2}$

As long as there is a population with imperfect inheritance of their characteristics, and not all of them have the potential to survive, then Darwinian evolution will occur. Sidney Winter (1987, p. 617) also expressed the idea that Darwinism could have a wider applicability:

In sum, natural selection and evolution should not be viewed as concepts developed for the specific purposes of biology and possibly appropriable for the specific purposes of economics, but rather as elements of the framework of a new conceptual structure that biology, economics and other social sciences can comfortably share.

The idea of Universal Darwinism has also been applied to the development of neural connections in the brain, the immune system, and computer viruses (Edelman, 1987; Plotkin, 1994; Aunger, 2002). These are cases not merely of analogy, but of the existence of processes that are actually evolving in accord with basic Darwinian principles of variation, inheritance and selection. Significantly, Gary Cziko (1995) describes the acknowledgement of such a 'universal selection theory' as 'the Second Darwinian Revolution'.

As such, Darwinian evolution is not tied to the biological specifics of genes or DNA. On Earth, DNA has the capacity to replicate. But other mechanisms of replication or inheritance may exist, on this planet and elsewhere. One possible and relevant example is the propensity of human beings to communicate, conform and imitate, making the replication or inheritance of habits and ideas a key feature of human socio-economic systems.

'Universal Darwinism' is not a version of biological reductionism or 'biological imperialism' where an attempt is made to explain everything in biological terms. The existence of Darwinian mechanisms also does not mean that the process involved is always that of genetic variation and selection. On the contrary, Universal Darwinism upholds that there is a core set of general Darwinian principles that, along with essential and auxiliary explanations specific to each scientific domain, may apply to a range of phenomena. Universal Darwinism encompasses a wide range of possible mechanisms. But they would share the common features of variation, inheritance and selection.

Darwinian principles apply by virtue of the existence of variety, inheritance and selection. In particular, by recognition of the ontological priority and replenishment of variety in both natural and social systems, Darwinian 'population thinking' is also relevant for social scientists (Mayr, 1982; Metcalfe, 1998). Accordingly, although the detailed mechanisms of change at the social level are quite different from those described in biology, socio-economic evolution is still Darwinian in several important senses.

However, while all evolving systems may be subject to a core set of Darwinian principles, the notion of Universal Darwinism itself provides no alternative to a detailed explanation of the particular emergent properties and processes at the social level. Acceptance of Universal

\footnotetext{
2 See Hodgson (2001a) and Knudsen (2001). Another widespread mistake is to see artificial selection as a rival or alternative to natural selection. This misconception is criticised in Dennett (1995) and Hodgson (2003a, 2004). On the contrary, as Darwin (1859) himself showed, artificial selection is a special case and exemplar of natural selection.
} 
Darwinism does not provide all the necessary causal mechanisms and explanations for the social scientist, nor obviate the elaborate additional work of specific investigation and detailed causal explanation in the social sphere (Hodgson, 2001b).

Neither Universal Darwinism nor the theory of selection can give us a full, detailed explanation of evolutionary processes or outcomes. At the centre of Darwinism there is a rigorous theory, but it explains little on its own and it is thus placed in the context of a mass of empirical material (Hull, 1973). Darwinian principles provide a general explanatory framework into which particular explanations have to be placed.

To recapitulate, Darwinism includes not only specific theories that explain particular biological mechanisms, but also a general theory that applies to all evolving systems where there is inheritance, variation and selection, with possible differences in the detailed mechanisms involved. Accordingly, Darwinism has some unavoidable importance, at the general theoretical as well as the specific analogical and metaphorical levels.

The application of Darwinian principles to socio-economic phenomena depends crucially on the existence of variety, mechanisms of inheritance, and processes of selection in that domain. If meaningful inheritance or selection does not exist, then Darwinian principles do not apply. Clearly, the identification of these processes depends crucially on precise definitions of inheritance (or replication) and selection. Some progress is beginning to be made in these areas. Sections 2 and 3 of this essay summarise recent work that applies adequate definitions of replication and selection to socio-economic phenomena. Having considered replication and selection, we are in a position to consider an additional distinction, between a replicator and an interactor. This is established in Section 4.

\section{The Meaning of Replication: Habits and Routines as Replicators}

We now address the definitions of replication and selection. The detailed processes of replication are very different in society and in nature. If one term is to be applied in both areas then it must be defined fairly broadly, but not too broadly or imprecisely to risk a loss of meaning.

Some see the 'meme' as the replicator (Dawkins, 1976; Blackmore, 1999). However, meme enthusiasts cannot agree on what a meme is. Is the meme an idea, an instruction or some behaviour? In any case, if a meme is a replicator, then what structure is passed on? This analytical problem leads Dan Sperber to probe the meaning of replication and to suggest that it involved elements of causation, similarity, information and transfer. He then argues that many cases of so-called memetic replication are not true replication and that the 'grand project of memetics ... is misguided' (Sperber, 2000, p. 173). ${ }^{3}$

Peter Godfrey-Smith - another memes sceptic - offers another useful refinement of the replicator concept. For Godfrey-Smith (2000, p. 413): 'The ... job of explaining the heritability of variation, in the sense relevant to evolution by natural selection ... is the proper one for the replicator concept.' Godfrey-Smith then (2000, pp. 414-15) constructs the following definitions:

\footnotetext{
${ }^{3}$ Note also the statement by Godfrey-Smith (2000, p. 405) that the Dawkins-Hull concept of replication 'has two main elements, a resemblance between copy and copied, and some suitable causal relation linking the copy to the copied.'
} 
$\mathrm{Y}$ is a replicate of $\mathrm{X}$ if and only if: (i) $\mathrm{X}$ and $\mathrm{Y}$ are similar (in some relevant respects), and (ii) $\mathrm{X}$ was causally involved in the production of $\mathrm{Y}$ in a way responsible for the similarity of $\mathrm{Y}$ to $\mathrm{X}$. Replication is any process by which a replicate is produced.

Godfrey-Smith's definition requires similarity 'in some relevant respects', but does not specify what is 'relevant'. In an innovative volume, Robert Aunger (2002) refines Sperber's (2000) definition of replication. He argues that in general, replication is a relationship between a copy and some source exhibiting the following characteristics:

- Causation: the source must be causally involved in the production of the copy

- Similarity: the copy must be like its source in relevant respects

- Information transfer: the process that generates the copy must obtain the information that makes the copy similar to its source from that same source; and

- Duplication: during the process, one entity gives rise to two (or more). ${ }^{4}$

For Aunger, the first condition (causation) implies no more than that the original replicator must participate in the process that results in the appearance of its copy. The fourth criterion (duplication) - added by Aunger to Sperber's definition - is a feature of replication that is not necessarily found in other forms of inheritance. In other words, according to Aunger, replication is a special a type of inheritance where duplication is involved. Note also that Aunger's definition requires similarity 'in relevant respects', but again does not specify what is 'relevant'.

Aunger (2002) regards a meme as essentially the state of a node in a neuronal network capable of generating a copy of itself in either the same or a different neuronal network, without being destroyed in the process. Part of the problem with the original meme concept is that it referred to ideas, not to material entities or structures, without enough consideration of the material substrate of the 'information' in the meme or of the physical mechanisms of replication. Aunger's dramatic reworking of the meme concept overcomes these limitations. But by driving the meme concept into the neuron, Aunger moves away from the communication and cultural transmission of identifiable ideas, which memetics originally attempted to address.

Being uneasy about the very idea of a meme, we propose here a different approach. Instead of memes, we propose two alternative and mutually related concepts: habits and routines. Learning from the debates and difficulties within memetics, we give these alternative ideas greater meaning and refinement.

We follow the conception of habit found in pragmatist philosophy and instinct psychology, of an acquired propensity or disposition, which may or may not be actually expressed in current behaviour. ${ }^{5}$ Habits are formed through repetition of action or thought. They are influenced by prior activity and have durable, self-sustaining qualities. The issues of behavioural reinforcement or constraint may also be important here, but they relate to how and why behaviour comes to be repetitive. Habits are the basis of both reflective and nonreflective behaviour. But habit does not mean behaviour; it is not itself a recurrent or

\footnotetext{
4 Aunger (2002) treats replication as a special case of inheritance that involves copies that coexist for a while. Similarly, Nanay (2002) argues that 'non-trivial' replication means that 'new, spatially distinct entities' are formed in the replication process.

5 See principally James (1890) and Dewey (1922). For modern writers with a similar conception of habit see Margolis (1994), Murphy (1994) and Kilpinen (2000).
} 
repeated act. If we acquire a habit we do not necessarily use it all the time. It is a propensity to behave in a particular way in a particular class of situations. 'The essence of habit is an acquired predisposition to ways or modes of response' (Dewey, 1922, p. 42). Crucially, we may have habits that lie unused for a long time. Habits are submerged repertoires of potential behaviour; they can be triggered by an appropriate stimulus or context. Veblen and the pragmatist philosophers saw habit as something that may exist even if it is not manifest in behaviour. Habits are themselves means of higher deliberation and conscious resolve.

How are habits replicated? Unlike the replication of DNA or computer viruses, habits do not directly make copies of themselves. Instead they replicate indirectly, by means of their behavioural expressions. They can impel behaviour that is consciously or unconsciously followed by others, as a result of constraint, convention, incentive or imitation. In this way, the maintenance of customs involves the replication of habits. It is possible, but not always necessary, that codifiable rules or instructions are also involved. It is well established that not all knowledge is codifiable: there is a difference between 'knowing how' and 'knowing that' (Ryle 1949; Polanyi, 1967). Eventually, the copied or conformist behaviour becomes rooted in the habits of the follower, thus transmitting from individual to individual an imperfect copy of each habit by an indirect route. ${ }^{6}$

The replication of habits satisfies Godfrey-Smith's (2000) definition and all four of Aunger's (2002) criteria for replication. The habit in one person causes behaviour that is copied and leads to similar habits being acquired. The acquired habit is similar to the first with respect to the behaviour it might promote under specific conditions. Some kind of tacit or other information is transferred in the process. And because copying of behaviour is involved, duplication is also present.

Note, however, that unlike the gene, the similarity applies to the manifest behaviour that derives from the habit. There is no necessary similarity in the neural configurations or psychological states of the individuals involved. But manifest behavioural similarity must exist, for it to be meaningfully described as a similar habit. In other words, essential similarity exists at the phenotypic and behavioural rather than the genotypic level. ${ }^{7}$ It is very different with the replication of genes. With genes, replicative similarity applies to the genetic coding, which may give rise to a significant degree of similarity at the phenotypic level as well. In contrast, with habits, replicative similarity is necessarily present at the behavioural level, but unlikely at the neural or genotypic level.

Habits are acquired and imprinted instruction systems in an individual, made up of elements that direct its behaviour or growth. A 'Lamarckian' possibility emerges here because the replication of habits proceeds by the replication of manifest behaviour, rather than of the particular 'software' of the habits themselves. Because the replication of habits works through the phenotypic and behavioural level, any additional behavioural characteristics that do not relate to the original habit might also be transmitted to the receiver. Despite the original propensity to behave in a particular way, the actual sequence of behaviours can be modified.

\footnotetext{
6 The replication of habits of thought is more complex, because thoughts are not always manifest in behaviour. Nevertheless, habits of thought are replicated, such as in the education system. Linguistic and other forms of communication are clearly important in this context. We postpone discussion of this issue to another paper.

${ }^{7}$ We use the term phenotype in the loose but widely accepted sense of the actual manifest organism and its traits, whereas genotype refers to the underlying genetic coding, an information set containing the instructions upon which the development of the organism and its traits partly depend.
} 
Hence with habits, acquired characters can be inherited. The reason is simple: habit replication itself works through characteristics, not through the direct replication of the generative structures. ${ }^{8}$

However, while a Lamarckian possibility exists in social and cultural evolution, too much interference into 'genotypic' habits by capricious phenotypic behaviours would disrupt any beneficial selection process. Efficacious selection cannot occur if there is too much incidental 'noise' created by the interference of phenotypes (Maynard Smith and Szathmáry, 1999; Knudsen, 2002a). Consequently, we should look for mechanisms that maintain some fidelity in the replication of dispositions and rules in social evolution. If there is too much mixing or interference with replicators, then meaningful replication will not take place. This may be the case with at least some 'memes'. If replication is not meaningful, then 'Universal Darwinism' does not apply. Significantly, Michael Hannan and John Freeman (1989, pp. 22-3) argue that Lamarckian processes are unimportant in the population ecology of social organizations. According to them, selection takes places around deeply embedded and durable rules. Whether meaningful replication exists in socio-economic evolution is an empirical question, and invites further empirical and theoretical research.

Habits are replicated when we repeatedly follow the behaviour of others. For instance, there may be incentives or constraints. These can provide reasons to acquire specific customs, follow particular traffic conventions and use specific linguistic terms. In these cases, because others are acting in a particular way we can have powerful incentives to behave accordingly. In doing so, we too build up habits associated with these behaviours. The behaviours are reproduced and also the habits giving rise to them are replicated.

Another possible mechanism of replication is imitation. Imitation need not be fully conscious, and it will also involve some 'tacit learning' (Polanyi, 1967; Reber, 1993; Knudsen, 2002a). Perhaps imitation can occur even without strong incentives, on the grounds that the propensity to imitate is instinctive, and this instinct has itself evolved for efficacious reasons among social creatures (James, 1890; Veblen, 1899; Campbell, 1975; Boyd and Richerson, 1985; Simon, 1990; Tomasello, 2000). However, for instinctive imitation to take off, a substantial set of similar behaviours in the group must already have emerged for other reasons. Furthermore, if imitation is more than mimicry, then the rules and understandings associated with it also have to be transmitted. Imitation is more problematic than it appears (Aunger, 2002). Nevertheless, there are provisional grounds to consider a partially instinctive propensity to imitate as a strong element in the complex social glue, and hence a force behind the replication of habits. Once imitation becomes an established propensity, people may imitate others on the basis of status or other perceived advantages.

Like any replicator, habits do not stand alone. Genes require organisms to carry them, and these organisms are dependent on their environment. Genes exist on a biochemical substrate. Likewise, habits cannot exist apart from the human organisms in which they reside. They exist on a psycho-neural substrate; they are formed and stored in the individual human nervous system. This in turn depends on the development of each individual, involving both genetic and environmental influences. Habits depend crucially upon stimuli from the social environment. They are not unique in this respect. But habits differ from genes in their mechanism of replication, and habits do not have the potential durability and copying fidelity

\footnotetext{
${ }^{8}$ However, if the modification of a first person's actual behaviour alters the original propensity, and creates a new habit before replication in a second person takes place, then such an imitator would inherit characters that relate to genotypical attributes in the first person. Hence genotypic similarity would also exist.
} 
of the gene. In social evolution there are additional mechanisms to supplement habit replication, which often weed out or alter aberrant habits. Mechanisms of social conformity are particularly important (Henrich and Boyd, 2001). For example, if people have incentives to conform and disincentives to rebel, then these mechanisms can partially overcome the copying infidelities of habit replication.

In general, social institutions help to stabilise and channel behaviour and habits. Societies with effective institutions in this regard may have advantages over others. In particular, firms with incentives and culture to stabilise productive patterns of behaviour may have advantages over their competitors. At the same time, as generally in evolution, there must be scope for a degree of variation and innovation.

Having pointed to the social context of individual habit replication, we now consider routines as possible replicators. Michael Cohen et al (1996, p. 683) define a routine as 'an executable capability for repeated performance in some context that [has] been learned by an organization in response to selection pressures.' A consensus has now emerged that routines relate to groups or organizations, whereas habits relate to individuals (Dosi et al., 2000, p. 5). Just as individuals have habits; groups have routines. We regard routines as the organizational analogue of habits. But we do not refer here to habits that are simply shared by many individuals in an organization or group. Routines are not habits: they are organizational metahabits, existing on a substrate of habituated individuals in a social structure. Routines are one ontological layer above habits themselves.

Like habits, routines are dispositions rather than sets of behaviours. However, confusion between dispositions and behaviours has played havoc in the literature on routines. Nevertheless, the prevailing view now seems to be that routines should be treated as organizational dispositions (Hodgson, 2003b). For instance, Nelson and Winter (2002, p. 30) suggest that routines are dispositions when they write: 'we treat organizational routine as the organizational analogue of individual skill.' Both routines and habits are similar to genotypes, rather than to behavioural phenotypes.

In sum, we define routines as organizational dispositions to energise conditional patterns of behaviour within an organized group of individuals, involving sequential responses to cues. Just as habits are elements of human learning and cognition, the building and replication of routines involves organizational learning and the transmission of knowledge. Routines are nevertheless manifestations of human cognition and the interactions of individual minds. To understand how routines work, and the particular role of behavioural cues, it is necessary to consider how any tacit or other information associated with a routine is preserved and replicated. Michael Cohen and Paul Bacdayan (1994) use the distinction in psychology between procedural and other, more cognitive forms of memory, such as semantic, episodic or declarative memory. Procedural memory is triggered by social or other cues. 'Procedural knowledge is less subject to decay, less explicitly accessible, and less easy to transfer to novel circumstances' (Cohen and Bacdayan, 1994, p. 557).

Routines depend upon a group of individuals, each with habits of a particular kind, where many of these habits depend upon procedural memory. The behavioural cues by some members of a structured assembly of habituated individuals triggers specific habits in others. Hence various individual habits sustain each other in an interlocking structure of reciprocating individual behaviours. 'A process of habit-meshing takes place within any organization, in that each person's habits are a part of the environment of the others' (Campbell, 1965, p. 27).

The organization or group provides a social and physical environment for each individual. This environment is made up of the other individuals, the relations between them and the 
technological and physical artefacts that they may use in their interactions. This social and physical environment produces cues that can trigger behaviours, which in turn can trigger the behaviour of others, perhaps produce or modify some artefacts, and help to change or replicate parts of this social and physical environment.

Partly because of procedural memory, organizations can have important additional properties and capacities that are not possessed by individuals, taken severally. The organization provides the social and physical environment that is necessary to cue individual habits and deploy individual memories. If one person leaves the organization and is replaced by another, then the new recruit may have to learn the habits that are required to maintain specific routines. Just as the human body has a life in addition to its constituent cells, the organization thus has a life in addition to its members. A routine derives from the capacity of an organization to energise a series of conditional, interlocking, sequential behaviours among several individuals within the organization.

Routines are not behaviour; they are stored behavioural capacities or capabilities. These capacities involve knowledge and memory. They involve organizational structures and individual habits which, when triggered, lead to sequential behaviours. Consider a firm in which all employees and managers work on weekdays only. During the week a number of organizational routines can be energised. At other times the firm is inactive. But the routines do not all disappear at the weekend, to reappear mysteriously the next Monday morning. The routines-as-capacities remain. They can be triggered next week by appropriate stimuli.

Just as habits replicate from individual to individual, routines replicate from group to group and from organization to organization. In studies of technological diffusion, organization studies, and the strategic management literature there is some discussion of the diffusion or replication of routines. ${ }^{9}$ Prominent mechanisms for the replication of routines involve the movement of employees from organization to organization, or independent experts or consultants that help to transfer knowledge and experience gained in one context to another. The case studies show the transfer of technologies, management procedures, corporate multidivisional structures, accounting conventions and much else. What is central to these transfers is the replication of practices and organizational relationships. What is generally critical is the capacity of the receiving organization to accommodate and utilise these practices and relationships in the context of its own ingrained culture of habits and beliefs.

In some respects the replication of routines may be more difficult than the replication of habits from individual to individual. Take the mechanism of imitation. Among individuals, any evolved capacity to imitate others must involve the ability to sense the more significant actions, and the tacit rules and meanings associated with behaviour. This capacity would have evolved over millions of years. By contrast, complex organizations are extremely recent in human history. Many organizations may have evolved only limited capacities to discern and prioritise the important rules and meanings. It is likely that replication through imitation is even more difficult with (and at the level of) organizations than it is with individuals.

Nevertheless, as noted in the organization studies literature, examples of successful routine replication exist. They typically involve the combination of codifiable information and instructions with extensive personal example, advice and contact, where the receiving

\footnotetext{
${ }^{9}$ For case studies see Aldrich and Martinez (2003), DiMaggio and Powell (1983), Hannan and Freeman (1984, 1989), Lazaric and Denis (2001), Levitt and March (1988), Rogers (1995), Stinchcombe (1990), Szulanski (1996, 2000) and Zucker (1987).
} 
organization has sufficient plasticity to usefully absorb and accommodate the routine. Sometimes routines are spread or cloned as a result of laws or rules that emanate from a third organization, such as the state or an association of employers. The replication of routines can also occur through a cloning strategy by a receiving organization. Or it can result from lowerlevel contacts, stimulation and imitation, between several individuals. Do these processes exhibit the four criteria of causation, similarity, information transfer and duplication, and thus qualify as true replication? Causal involvement is present, because the new routine would not be created without the existence of a precursor from which it was copied. Clearly, the other three definitional features are there as well. Routines replicate, and they do so on a substrate of organized and habituated individuals.

The qualities that make up good replicators are longevity, fecundity and fidelity (Dawkins, 1976). Clearly, in regard to longevity and copying fidelity, habits and routines are much inferior to genes. But they have potential degrees of durability and copying fidelity that warrant their status as repositories of knowledge and custom. The designation of habits and routines as replicators depends upon this fact.

At the same time, because the copying or replication of habits and routines is imperfect, herein lies a source of variation in the evolutionary process. Such variation can occur by accident, experiment or design, and detailed consideration of this issue is relevant to any application of Darwinian evolutionary principles (Campbell, 1965; Metcalfe, 1998). ${ }^{10}$ Habits and routines are elements within the firm that influence, constrain and create possibilities for future variation. There are important ways in which the generation of variety in a population of evolving firms differ from the generation of variety in a population of evolving biological organisms. However, it is not possible to deal with the specifics here. We simply note that variation is the evolutionary fuel, and the necessary basis for selection to work in any population, including a population of evolving firms.

\section{The Meaning of Selection: The Selection of Habits and Routines}

A consensus has emerged in modern attempts to refine the concept of selection. A number of selection theorists, working with both philosophical and mathematical tools, have generalised the concept of selection to apply to diverse populations of entities. Within this literature, after the seminal contribution of Ronald A. Fisher, the formalisation of general selection theory by George Price has been highly influential.11

Two fundamentally different concepts of selection are employed in biology and elsewhere, but both are encompassed by the general selection theory developed by Price. One type of selection involves the creation of a subset of elements from a broader set, by some process or criterion. Such selection is equivalent to choosing apples from a fruit stall. Price (1995) termed this subset selection. When Darwin discussed selection he did not consider subset selection, because offspring are not a subset of parents. Price's definition unifies both the

10 Knudsen (2002b) provides a typology of the many sources of variety that are present in Nelson \& Winter's (1982) evolutionary theory of eonomic change, including variety that comes from changes in routines.

11 Fisher (1930), Campbell (1965), Price (1970, 1972, 1995), Sober (1984), Hull (1980), Hull et al. (2001), Darden and Cain (1989), Sober and Wilson (1998), Frank (1998), Hofbauer and Sigmund (1998), Nanay (2002), Kerr and Godfrey-Smith (2002b), Henrich (2004). 
selection of successors (we shall call this successor selection) and subset selection. Price defined selection in terms of two sets that exist in successive time steps. A set exists at the first step, and a corresponding set exists at the second step.

The first may be described as the anterior set, the second as the posterior set. A necessary condition for selection is when all the elements of the posterior set are sufficiently similar to elements within the anterior set. Furthermore, every element in the posterior set must have crucial material or informational features that correspond to, or are derived from, features of a corresponding member of the anterior set. Similarity between members of the two sets can be established by mechanisms of replication or inheritance, as in the case of successor selection, or it is a matter of enduring identity, as in the case of subset selection. But some such mechanism of succession or endurance is connoted by the definition of selection. Hence this generalised concept of selection ties in with, and relies upon, additional mechanisms that preserve crucial material or informational features through time.

We have noted that Price's definition of selection is so broad that it does not rely on replication or inheritance. Neither does it rely on the distinctions between genotype and phenotype, nor between replicator and interactor. Nevertheless, the replicator-interactor distinction is important in socio-economic evolution, as understood here.

Another milestone in the development of general selection theory is the work of Hull et al. (2001). Starting from our knowledge of specific but different mechanisms of selection in the real world, they derive some general principles. They offer a general account of selection that covered the very different processes of gene selection, the selection of antibody-producing cells in the evolution of the immune system, and operant conditioning. ${ }^{12}$ A crucial goal is to provide an account of selection that was neither too broad nor too narrow. They define selection as 'repeated cycles of replication, variation, and environmental interaction. These three processes must be so structured that environmental interaction causes replication to be differential' (pp. 526-7). They stress that selection combines replication with environmental interaction. The combination of refinement and generality in their account makes it a source of inspiration for theories of selection at the socio-economic level.

Inspired by this literature, we define selection in the following terms. Selection involves an anterior set of entities, each interacting with their environment, thereby being transformed into a posterior set, where all members of the posterior set are sufficiently similar to some members of the anterior set, and where the resulting frequencies of posterior entities depend upon the properties of the members of the anterior set evaluated in their environmental context. The environment of any entity can in principle include other existing entities.

Note that when the distinction between genotype and phenotype is relevant, the above definition can be applied to both the selection of phenotypes and selection for genotypes. This invokes the distinction of Elliott Sober (1984) and others between 'selection of' and 'selection for'. Selection in the above definition would apply to the selection of phenotypes such as individual organisms, with the concomitant selection for associated genotypes. The Priceinspired definition of selection is so broad that it covers both selection of and selection for.

We first address the selection of habits. In the light of the previous discussion it becomes clear that not one, but two types of selection process are involved. Only one of them relies on

\footnotetext{
12 In his response to Hull et al. (2001), Cziko (2001) argues that behaviours are not units of selection, rather the purposes or propensities that give rise to behaviour. This dovetails with our insistence that habits and routines are dispositions, not behaviours.
} 
mechanisms of habit replication as discussed in the preceding section. This is because subset selection of habits also exists. Subset selection of habits occurs within the repertoire of habits held by an individual, or group of individuals. Habits can decay if we do not reinvigorate them by repeated use. Our knowledge of a foreign language can diminish, our mathematical aptitude can waste away, or we can lose the habits of our youth. At the same time, other habits are retained. A selected subset of habits is created through the disuse of other habits. This selection process occurs through interaction with the environment. The posterior set is related to the anterior set, and the frequencies of posterior habits depend upon the properties of the members of the anterior set evaluated in their environmental context.

Consider the other possible process, successor selection of replicating habits. This involves the habits of one individual being replicated in other individuals. The possible mechanisms involved, such as imitation, incentives and constraints, are discussed above. The anterior set is composed of habits held by an individual or group of individuals. Holding the population of individuals constant to exclude migration, the posterior set includes the habits newly copied by some individuals in addition to the habits retained by some of the individuals. Again, this occurs through interaction with the environment, including interactions between individuals. The posterior set is related to the anterior set, in the respects indicated in the discussion of habit replication above. When the frequencies of posterior habits depend upon the properties of the habits of the anterior set evaluated in their environmental context, this is an instance of successor selection. Quite commonly, some behaviours will be evaluated as more attractive, powerful, efficient or appropriate than others within a particular context and will therefore tend to be copied by many individuals. Some behaviours will be less favoured and therefore copied only by a few individuals. This copying of behaviours will lead to the replication of habits, as noted above.

Turning to the selection of routines, as with habits, there is both subset and successor selection. Like habits, routines can decay if they are not reinvigorated by repeated use. The decay of a routine involves the waning of some or all of the interlocking individual habits that are necessary to sustain the routine, or the removal of one or more individuals from the group that performs the routine. A posterior subset of routines is created. This posterior subset is related to the anterior set. The frequencies of posterior routines depend upon the properties of the anterior routines, in that efficacious or favoured routines will be selected.

The successor selection of routines depends upon the processes of routine replication that were briefly discussed in the preceding section and in the case study literature cited therein. The anterior set is composed of routines involving a group or groups of individuals. The posterior set includes routines, newly acquired in addition to the routines retained by some of the individuals. Again, this occurs through interaction with the environment, including interactions between individuals and groups of individuals. The posterior set is related to the anterior set, as indicated in the discussion of routine replication above.

When we consider routines in the context of the firm, some selection occurs as a result of the decline or failure of the firm as a whole in its interactions with its external environment. Also managerial inattention following large periods of success might play an important role in promoting the inertia that leads to the decline of a firm (Miller, 1994). Alternatively, some selection may result from internal managerial action, due to perceptions of the relative efficiency of different routines (Miner, 1994). Such internal selection, involving perceptions of efficacy rather than the test of the external environment, is an example of 'vicarious selection' as discussed in a classic paper by Donald T. Campbell (1965). By internal or external mechanisms, some routines are copied more than others. The frequencies of posterior 
routines thus depend upon the actual or perceived properties of the anterior routines as required to make this an instance of successor selection. In sum, we have good reason to consider both habits and routines, as replicators and as units of selection. Furthermore, both habit selection and routine selection appear in the two possible modes of subset selection and successor selection. However, there is an important difference between habits and routines. Habits do not require a cohesive group of individuals. The subset selection of habits can occur with a single individual. Successor selection of habits requires interactions between individuals, but not necessarily enduring relations or cohesive groups. By contrast, all routine selection and replication involves a group of individuals that is sufficiently cohesive and interactive to maintain the interlocking individual habits that energise the routine. This raises deeper questions about the social and organization context of routine replication and selection. These are addressed in the next section.

\section{The Firm as an Interactor}

Originally, Richard Dawkins (1982) distinguished between 'replicators' and 'vehicles'. However, Hull $(1980,1981,1988)$ proposed the alternative term of 'interactor', to stress not only the cohesive nature of the replicator-carrying unit, but also its interaction with its environment. Hull (1988, p. 408) defines an interactor as 'an entity that directly interacts as a cohesive whole with its environment in such a way that this interaction causes replication to be differential'. Later below we shall suggest some refinement of this definition.

Robert Brandon (1996, p. 125) remarked that the distinction between replicators and interactors 'is best seen as a generalization of the traditional genotype-phenotype distinction'. This generalization seems straightforward in genetic evolution, as the organism is both the phenotype, and the cohesive whole that interacts with the environment, causing differential replication of the genes in the population. However, even with genetic evolution the neat distinction between genes as replicators and organisms as interactors is illusionary. A closer look reveals that also lengths of RNA, lengths of DNA, chromosomes and gametes function as interactors (Brandon, 1998; Hull, 1988, 2001). Not only are there biological interactors at a level lower than the gene, the concept of phenotype has been 'extended' to go beyond the organism and its behaviour (Dawkins, 1982), and even groups, populations and species are considered as possible interactors (Brandon, 1998; Hull, 1988, 2001). Furthermore, the boundaries of phenotypes and interactors become more difficult to determine with evolution in the neural and immune systems. These definitional problems become even greater in the socio-economic domain.

So far in this article we have used the term phenotype in the loose but widely accepted sense of the manifest behavioural and other attributes (traits) of an interactor. We have argued that habits and routines are gene-like replicators, and we have used the term phenotype to refer to their manifestations, including behaviour and other attributes. A problem is to determine the identity of the interactor. In refining the concept of the interactor we find that it has features that are additional to the looser concept of a phenotype. There are two crucial, additional and related elements in the definition of an interactor. First, it interacts with its environment as a cohesive unit. Second, these interactions cause differential replication of the replicators. Clearly, as in the case of genetic evolution, an interactor may encompass a number of replicators. 
As explained above, two types of selection process can operate. However, subset selection does not involve replication. To identify interactors we must look at successor selection and mechanisms of differential replication.

Again consider habits. With successor selection some but not all habits are passed on to others. The obvious candidate for the interactor in this context is the human individual; it satisfies the definitional conditions outlined above. An individual can interact with nature, and often also with other humans. Notably, interaction with others involves more than biological attributes. Human individuals adopt social roles (e.g. friend, foe, thief) that are part of meaningful social interaction.

But we must also consider why a group of individuals is not best regarded as the interactor for habits. This is because habit transmission is essentially from individual to individual, not from group to group. Interactions between individuals in one group may occur, but some habit replication can occur without them, and the group does not necessarily have to be cohesive for replication to occur. Instead, the individual is the essential and cohesive unit in the replication of habits.

By contrast, if the replication of habits does critically depend on interactions within a group, then the structures of interlocking relationships that enable these interactions have also to evolve and endure. These structures have also to be considered as replicators. Something more than the aggregate of individuals is involved. This is where routines come in. Routines replicate from group to group, and involve interlocking relationships and interactions within each group.

Consider a team of workers within a firm, concerned with some aspect of the firm's productive activity. This team is made up of individuals and routines. Can such a team be considered as an interactor? If the answer is positive, then we must be able to point to interactions between the team and its environment that might cause the replication of the routines involved to be differential.

We are thus concerned with successor selection and the replication of routines from team to team. Such replication could occur if the management of the firm decides to build another plant and build up a second and similar production team. In this case the management of the firm is causally implicated in the replication process. Another possible mode of replication is the copying of the team type and its routines by another firm. What is notable in these examples is that the firm, as well as the team itself, plays a crucial causal role in team replication.

This does not disqualify routines within the team from being replicators. But it does not make the team an interactor. Compared with the definition of a replicator, the definition of an interactor entails the additional criterion that the entity must interact with its environment as a cohesive unit, so causing differential replication. We interpret this criterion to disqualify entities that also require strong and enduring connections with further entities to bring about differential replication.

Many cohesive wholes exist in nature, but only a few of them count as interactors in a selection process. According to Hull (1988, 2001) chromosomes, gametes, organisms, and possibly populations and species interact as cohesive wholes with their environment in a way that replication is differential, i.e., some structures become more rare, some more common. In the primordial soup, it is likely that the first self-replicating entities involved in the earliest evolution were both replicators and interactors, but genes are primarily replicators (Brandon, 1998; Eigen et al. 1981). The gene evolved to fulfil a specialised function as a replicator 
whereas its host organism both provides it with a suitable cellular environment and fulfils the specialised function as an interactor (Hull, 1988, 2001).

Just as genes require very strong connections with organisms in order to bring about differential replication, so too do routines and teams require strong connections with the firm for differential replication to occur. For this reason we do not generally consider teams within firms to be interactors. In earlier times when production was organized in a team of hunters, the team was an interactor, but today it is not because it depends on strong and enduring connections with a host firm. The team has evolved to fulfil a specialised function as a replicator whereas its host firm both provides it with a suitable environment and fulfils the specialised function as an interactor.

However, this interpretation depends critically on the understanding of terms such as 'cohesive' and 'strong'. At this point it is necessary to add some refinements to the definition of an interactor. The term 'cohesive whole' indicates that its components stick together and remain united. We interpret this to mean at least that all the components depend critically on the survival of the whole, and that to some degree the components depend on the survival of each other.

We define $p_{i, j}$ as the probability, with respect to a given environment, that entity $i$ will expire if entity $j$ expires. By a given environment, we refer to a set of possible environmental states that are similar in relevant respects. Each interactor is a cohesive whole and for each interactor there is a corresponding non-empty 'component' set of replicators $R$. There is also a positive number of replicators or interactors that are not members of $R$. If an entity $w$ is an interactor, then it must satisfy all of the following minimal conditions:

(1) For every member $r$ of $R, p_{r, w} \geq 1-\varepsilon$.

(2) Every member $r$ of $R$ must be a component part of $w$, in the further sense that every $r$ is part of the structure of $w$, and interacts with the outside world through $w$.

(3) For every replicator or interactor $x$, which is not a member of $R, p_{x, w}<\varepsilon$ and $p_{w, x}<\varepsilon$.

(4) Every $w$ has a set of properties $C_{w}$ that will determine the expected number of successors of $R$ within a given environment.

Where $\varepsilon$ is a small positive number. The first of these minimal conditions means that if the cohesive whole perishes, then all the 'component' replicators are also likely to perish. This implies some minimal cohesion and - given that some members of this population are not members of $R$ - it creates the possibility of differential replication among a whole population of similar types of replicator. The second condition elaborates slightly the status of members of $R$ as components of $w$. The third condition requires that if the cohesive whole expires, then there is a high probability that all non-component entities will survive. The third condition also requires that if any non-component entity expires, then there is a high probability that the cohesive whole will survive. The third condition means that the cohesive whole and any noncomponent entity are independent in the sense that the survival of one does not entirely depend on the survival of the other. The first three criteria define an interactor as a cohesive whole within a given environment. The fourth criterion defines an interactor as an entity that will cause differential replication within this environment. It is a matter of debate whether these conditions are sufficient to define an interactor; here we simply uphold that they are necessary.

Consider whether the firm satisfies the necessary conditions for being an interactor. Its component replicators are a set $R$ of routines. Note that the habits or genes of individual 
members of the firm cannot be members of $R$. Their inclusion would violate the first condition, as neither the habits nor the genes of individuals are highly likely to be exterminated if the firm expires. These habits or genes are not components of the firm. By contrast, the particular routines that are members of $R$ are likely to expire if the firm ceases to exist. The first condition is thus satisfied. Routines are also components of the firm in the sense of the second condition. The third condition is not violated, because there is no replicator or interactor outside $R$ whose expiration would likely result in the demise of the firm, or would itself be likely to expire if the firm went bust. The fourth criterion requires that the properties of the firm determine the expected number of its particular routines within a given environment. Depending on the firm's ability to interact with its environment, its routines must become more rare or more common. As the historical record shows, this requirement is fulfilled because other firms will copy the routines of the more profitable firms, and because the more profitable firms will expand by copying their own routines. The firm thus qualifies as an interactor, at least by these minimal and preliminary conditions.

We now consider whether these conditions apply to the team. The replicator components of a team would again be routines. Clearly, and at least by the second condition, the firm that hosts the team is not a member of $R$. Given that the firm is an interactor, and not member of $R$, then much hinges on whether the team violates the third condition. Is the team likely to expire when the firm expires? If the answer is 'yes', then by the third condition, the team is not an interactor.

On the one hand, often the survival of the team depends critically on the survival of the firm. In these cases, if the firm goes bust, then the team dissolves. On the other hand, there are cases when one firm merges with, or is taken over by, another firm. This absorption of one entity into another may keep much of the features of the original entity intact. Hence the team can survive the merger or acquisition of its host firm. By contrast, in the natural world, the absorption of one organism by another means the dissolution of one of these organisms. In the socio-economic world, much of the cohesion of an original firm can be retained when it is merged with or acquired by another firm; absorption does not necessarily mean dissolution.

These considerations oblige us to revisit the definition of $p_{i, j}$ and particularly the term 'expire'. Does a merger or takeover amount to an expiration of the original firm? The constitution, boundaries or title of the firm can change radically with a merger or acquisition. But on the other hand, many of its components, rules, property, routines and structures may remain intact. Some employees and customer goodwill may survive the metamorphosis. Clearly, merger or acquisition is not the same as bankruptcy or dissolution.

We have an intermediate case that is not typical of organisms in the natural world. When a cat eats a mouse, then the consumed interactor expires. But when the whale consumed the Biblical Jonah, he remained an interactor and atypically lived to tell the tale. With the takeover of one firm by another, the legal identity of one firm may expire, but some of its teams and their routines may live on, like Jonah, in the belly of the predator.

There is a case for treating absorption, such as through merger and acquisition, as nonexpiration. Similarly, if the firm divides into separate units then that does not necessarily mean that it expires. The term expire must be taken to mean the loss of all coherence and structure. In the context of the modern firm, it means the complete loss, rather than the mere transfer or division, of the legal personhood of the firm. If this argument is accepted then the fate of the team is bound up with the fate of its host firm; if the firm in this stricter sense expires, then the team is also likely to expire. In this case the third condition is violated and the team is not an interactor. 
It is nevertheless conceivable that a team might outlive the expiration of its host and continues to interact as a cohesive whole within the environment provided by a new host. Whether this happens depends on the degree to which the team has developed strong and enduring connections with its original host. Teams are often disqualified as interactors because they will be dissolved if the host expires. This is the case if the team has evolved to fulfil a specialised function as a replicator whereas its host firm both provides it with a suitable environment and fulfils the specialised function as an interactor.

While we admit these possibilities, including in our definitions, the literature on mergers and acquisitions suggests that the survival of acquired teams or routines within the acquiring or merged firm is relatively rare. With mergers, managers have often found it very difficult to fully integrate the component parts of merged firms. Acquisitions tend to work out better when the unit acquired is relatively small and the acquiring firm breaks up and replaces the prevailing culture of the acquired firm (Kusewitt, 1985; Datta, 1991; Walter, 1991). Overall, teams and routines infrequently survive mergers or acquisitions intact. In sum, we do not entirely rule out the possibility of a team being an interactor, but we see the firm as more generally and powerfully fitting this role.

We favour a legally grounded definition of the firm (Blair, 1999; Soderquist, 2000; Hodgson, 2002a). This means that the legal identity of the firm is an important element, alongside others, in the capacity of the firm to protect its assets and remain a coherent whole. In the case of the takeover of one firm by another, or in the division of one firm into two or more separate entities, these legal assets, rights and capacities are often divided or passed on. The formal legal name of a particular firm may expire, but its assets, rights and capacities defined in law may endure. Such a conception of the firm is not essential to our argument but it strengthens our case. Its legal status is crucial in cohering its interactions with a market environment, and its competition or cooperation with other firms. In legal and meaningful sense it is firms, not teams, that contract with customers or suppliers. Even if the firm has multiple plants or divisions, the firm has a degree of cohesion resulting from its unitary legal status as a single 'legal person'. Despite widespread confusion in this area, no good reason has ever been given for economists to relinquish such a definition. At the same time it has to be recognised that there are other relevant structures, such as conglomerates, business units, joint ventures, and so on, which involve multiple firms. Some of these might also be interactors, but it is beyond the scope of this essay to consider these other entities. Instead we concentrate on the status of the firm as an interactor.

What concerns us here is the endurance or expiration of the organized substance that makes up a particular firm. This 'organized substance' refers to entities such as structures, rules and routines. To a large degree, the organized substance of a firm can survive merger, takeover or even division. The law itself speaks of the 'absorption' or 'purchase' or 'consolidation' or 'merger' of firms. By contrast, a firm expires when it becomes insolvent or bankrupt. ${ }^{13}$ In cases of insolvency or bankruptcy, a team that fulfilled a specialised function as a replicator within its now expired host firm is not likely to find a similar suitable environment and will therefore be dissolved.

The human individual is an interactor. Firms are made up of individuals and their interrelations. Hence, if firms are also interactors, then we have a hierarchy of interactors and

\footnotetext{
13 But there are examples of firms that appear to have more lives than a cat; they go bust to be re-opened the next day with unaltered structures and personnel, but new legal identities.
} 
evolutionary processes operating on more than one level. ${ }^{14}$ However, the existence of evolution on multiple levels does not necessarily involve replicators at different levels. At least one set of replicators must correspond to each level of interactor in a hierarchy of interactors, but there need not be a one-to-one correspondence between a hierarchy of replicators and a hierarchy of interactors (Brandon, 1998). Most rigorous accounts of multiple level selection establish a hierarchy of interactors, without necessarily establishing a corresponding hierarchy of replicators as well.

A good example of such a hierarchy is viable group selection. Despite being out of fashion for a while (Williams, 1966; Dawkins, 1976) the possibility of group selection is now rigorously established and widely acknowledged. ${ }^{15}$ However, group selection occurs under specific conditions only. The group itself has to be sufficiently cohesive and influential to overcome the adverse effects of immigration and emigration, thus minimising the possibility of altruistic and other group-oriented behaviours being diluted and undermined by free-riders. There must be differential success of groups, that is due in part to the properties of groups, not merely to their components. In general, a significant degree of group structure and cohesion are required to make group selection meaningful (Henrich, 2004). In short, group selection operates when the individuals in the group are bound together in a sufficiently cohesive manner to share a mostly common fate.

We suggest that the firm typically provides such structure and cohesion. The firm can provide a corporate culture and structured environment, consisting of behavioural norms and routinised practices, which can augment individual skills and output per person (Argyris and Schön, 1996; Hodgson, 1998). In this way the firm can sometimes be a more efficient means of organizing production than the market, even if it does not provide a sufficient advantage in terms of lower transaction costs (Hodgson and Knudsen, 2003). The importance of structured relationships within the firm, the effects of corporate norms and culture, and the consequential firm-specific capabilities and learning effects, mean that the firm typically has the necessary cohesion to qualify as an interactor.

Furthermore, the structures and routines within the firm largely and normally share the common fate of the firm itself. If the survival of the firm is jeopardised, then skilled individuals and much physical capital can be moved elsewhere. But the firm is not simply an aggregate of individuals, physical capital and codifiable knowledge. It also consists of idiosyncratic structures, relationships and routines that typically are not readily tradable and are specific to the firm itself (Winter, 1988; Langlois and Robertson, 1995). These routines are important repositories of knowledge that is not readily codified or sold. This means that most or all of the firm's routines share the fate of the firm in which they reside.

The competitive selection of cohesive groups such as firms is due to their differential properties in a common environment. In turn, these differential properties of firms partly emanate from the organized structure of the firms as a whole, and are not merely due to the aggregate properties of the individuals in the firm, taken severally. Structured and cohesive interactions between individuals within the firm give rise to, and are properly regarded as,

\footnotetext{
14 Multiple levels of evolution have been considered by many authors, including Lewontin (1970), Eldredge (1985), Boyd and Richerson (1985), Durham (1991), Maynard Smith and Szathmáry (1995), Brandon (1996), Sober and Wilson (1998), Keller (1999), and Kerr and Godfrey-Smith (2002a).

15 See, for example, Boyd and Richerson (1985), Hodgson (1993), Brandon (1996), Sober and Wilson (1998), Bergstrom (2002, 2003), Kerr and Godfrey-Smith (2002a).
} 
properties of the firm. These are a cause of differential profitability and thus differential replication of the firm's routines, i.e. competitive selection. This applies in the cases of both external selection (via inter-firm competition) and internal (vicarious) selection (by firm managers) of routines.

Given that they are units of selection, by the definitions discussed above this does not necessarily mean that the group or firm is also a replicator. If groups or firms are replicators, then we have to consider the interactors to which they relate. To avoid over-extending our argument, we here put aside consideration of whether a cohesive group or a firm can also be considered as a replicator. The crucial point here is that the existence of group selection depends on properties that simultaneously qualify the group as an interactor. As Robert Brandon (1996, p. 135) puts it: 'when selection occurs at a given level, the entities at that level must be interactors.' Accordingly, if firms are proper objects of selection, then that implies that they are interactors as well. ${ }^{16}$

There is a hierarchy of interactors, including firms at one level and individuals at another. There is also a hierarchy of replicators, namely routines, habits and genes. How do these two hierarchies relate? The distinction between 'selection of' and 'selection for' is relevant here (Sober, 1984). Just as the selection of individual organisms in genetic evolution results in selection for the corresponding genes, selection of firms in a competitive environment results in the selection for some of the replicators associated with the firms, such as their constituent routines. That is, the current properties of the firm determine whether its routines, and possibly the habits of its individual members, will be more common or more rare in the next time period.

Further descending the hierarchy, the selection of firms can also have a slight effect in the selection for human genes, given that employment opportunities in the firm can have an effect of the survival opportunities for human individuals. The selection of firms has effects that cascade down to the selection of individuals, and in turn to selection for genes. But selection for these lower-level, biological replicators can be ignored for purposes of analysing economic evolution. It is too slight to be of significance, given the much slower evolutionary processes involved.

The identification of the interactors involved in economic evolution has not previously received much attention. Yet, according to Brandon (1998, pp. 191-192), this question is of great importance because a hierarchy of replicators is derivative of an interactor hierarchy in the sense 'that we need to determine the level of interaction in order to determine the level of replication, but not vice versa.' What should count as an interactor is therefore of great importance for the advance of evolutionary theories of economic change.

We have reached the conclusion that a firm is typically an interactor. But clearly, this proposition has to be explored further, especially in the light of future definitional refinement of the terms involved. Nevertheless, the idea that the firm can be treated as an interactor, ties in directly with the idea that firms are selected through competition in a market environment,

16 Brandon (1996, p. 137) considers interdemic group selection, where groups are more or less reproductively isolated. In this case, group selection occurs between by processes of differential group extinction and propagation and hence 'the replicators are the groups themselves' as well as the gene replicators. However, Brandon's words were originally written in 1988, and before the recent definitional refinement of the concept of replication. 
and that this is part of one level of the full, multi-level selection theory that must be constructed in order to understand socio-economic evolution.

\section{Conclusion}

Our proposal that the firm can be considered as an interactor is consistent with the general line of argument in Nelson and Winter's (1982) work. They considered firms as units of selection in a competitive process and 'routines as genes'. We have endorsed and refined their perspective here, using insights from modern evolutionary theory and the philosophy of biology.

Many of these insights have been gained from the development of a framework of Universal Darwinism, where generalised Darwinian ideas are applied to non-biological, as well as biological, evolving systems. We have noted that this possible generalization of Darwinism has been raised by many authors in the past, long before the particular versions of Dawkins (1983) and Dennett (1995). The application of Darwinism to socio-economic evolution depends simply on the existence of meaningful variation, replication and selection in that sphere. Understanding this, in turn, depends on adequately precise definitions of those Darwinian concepts. Within evolutionary economics, over twenty years after the appearance of Nelson and Winter's (1982) classic work, these issues are only beginning to be explored.

As noted above, detailed exploration of the processes of replication and selection in any context requires the identification of the interactors and the levels of interaction. The contribution of this paper is, first, to establish in general and formal terms some of the essential characteristics of an interactor, applying to any evolutionary context. Second, on this basis, we have established the status of a firm as an interactor in socio-economic evolution.

The motivation has in part been to explore the possible generalization of Darwinism to this sphere. The applicability or otherwise of Universal Darwinism cannot be determined without such a conceptual, theoretical and empirically grounded exploration. Hitherto the pioneers of modern evolutionary economics have been content to treat the application of Darwinian principles as one of carefully choosing appropriate metaphors or analogies (Hodgson, 1993; Dosi et al., 2000). The challenge of Universal Darwinism is to go further, and to consider the possibility of a degree of ontological similarity at general level of the evolutionary process (Hodgson, 2002b). Such ontological similarity may occur alongside huge differences in the detailed mechanisms and processes of variation, replication and selection.

However, the exploration of the possibility of a generalization of Universal Darwinism to within evolutionary economics is not merely a matter of idle curiosity. It is our conviction that the further development of work in this genre requires the development of a conceptual framework alongside detailed empirical work. Indeed, the organization and success of the latter depends to a large degree on success in the former, as all empirical enquiry is prompted and framed by questions of theory. We concur with the sentiments of Hull (1978, p. 350) in one of the quotations that heads this article: empirical evidence on its own can have little impact, and scientific progress depends on the organizing scaffold of a theoretical system. As yet, Darwinism provides the only general evolutionary framework within which a complete causal explanation of evolutionary processes appears possible. Even advocates of selforganization theory and thermodynamic analogies admit this. ${ }^{17}$

17 See Hodgson (2002b) for evidence and discussion of this point. 
As many have claimed for civilization, socialism or Christianity, a Darwinian evolutionary economics has not really been tried. Despite Darwin's (1859) own hints at the possible application of his evolutionary principles to social as well as biological entities or processes, and despite the early attempts by Bagehot (1872), Ritchie (1896), Veblen (1899) and others to apply Darwinian principles to social evolution, a rigorous extension of these principles to evolutionary economics has yet to be fulfilled. Any rigorous generalisation of the concepts of replication and selection must rely on reasonably precise general definitions of these terms, which did not emerge until after 1990. In defining and identifying interactors, we hope to have made a small but important further step. 


\section{References}

Aldrich, Howard E. (1999) Organizations Evolving (London: Sage).

Aldrich, Howard E. and Martinez, Martha (2003) 'Entrepreneurship as Social Construction: A Multi-Level Evolutionary Approach’, in Acs, Z. C. and Audretsch, David B. (eds) (2003) Handbook of Entrepreneurial Research (Boston: Kluwer), pp. 359-99.

Argyris, Chris and Schön, Donald A. (1996) Organizational Learning II: Theory, Method, and Practice (Reading, MA: Addison-Wesley).

Aunger, Robert (2002) The Electric Meme: A New Theory of How We Think (New York: Free Press).

Bagehot, Walter (1872) Physics and Politics, or, Thoughts on the Application of the Principles of 'Natural Selection' and 'Inheritance' to Political Society (London: Henry King).

Baldwin, James Mark (1909) Darwin and the Humanities, $1^{\text {st }}$ edn. (Baltimore: Review Publishing).

Bergstrom, Theodore C. (2002) 'Evolution of Social Behavior: Individual and Group Selection’, Journal of Economic Perspectives, 16(2), Spring, pp. 67-88.

Bergstrom, Theodore C. (2003) 'The Algebra of Assortative Encounters and the Evolution of Cooperation’, International Game Theory Review, 5(3), September, pp. 211-228.

Blackmore, Susan (1999) The Meme Machine (Oxford: Oxford University Press).

Blair, Margaret M. (1999) 'Firm-Specific Human Capital and Theories of the Firm', in Blair, Margaret M. and Roe, Mark (eds) (1999) Employees and Corporate Governance (Washington, DC: Brookings), pp. 58-89.

Boyd, Robert and Richerson, Peter J. (1985) Culture and the Evolutionary Process (Chicago: University of Chicago Press).

Brandon, Robert N. (1996) Concepts and Methods in Evolutionary Biology (Cambridge and New York: Cambridge University Press).

Brandon, Robert N. (1998) 'The Levels of Selection: A Hierarchy of Interactors', in Hull, D. L. and Ruse, M. (eds) (1998) The Philosophy of Biology (Oxford: Oxford University Press), pp. 176-197.

Campbell, Donald T. (1965) 'Variation, Selection and Retention in Sociocultural Evolution', in Barringer, H. R., Blanksten, G. I. and Mack, R. W. (eds) (1965) Social Change in Developing Areas: A Reinterpretation of Evolutionary Theory (Cambridge, MA: Schenkman), pp. 19-49. Reprinted in General Systems, 14, 1969, pp. 69-85.

Campbell, Donald T. (1974) 'Evolutionary Epistemology’, in P. A. Schilpp (ed.) (1974) The Philosophy of Karl Popper (Vol. 14, I \& II). The Library of Living Philosophers (La Salle, Ill: Open Court), pp. 413-63.

Campbell, Donald T. (1975) 'On the Conflicts Between Biological and Social Evolution and Between Psychology and Moral Tradition’, American Psychologist, 30(12), December, pp. 1103-26. 
Cohen, Michael D. and Bacdayan, Paul (1994) 'Organizational Routines are Stored as Procedural Memory - Evidence from a Laboratory Study’, Organization Science, 5(4), November, pp. 554-68.

Cohen, Michael D., Burkhart, Roger, Dosi, Giovanni, Egidi, Massimo, Marengo, Luigi, Warglien, Massimo, and Winter, Sidney (1996) 'Routines and Other Recurring Action Patterns of Organizations: Contemporary Research Issues', Industrial and Corporate Change, 5(3), pp. 653-98.

Cziko, Gary (1995) Without Miracles: Universal Selection Theory and the Second Darwinian Revolution (Cambridge, MA: MIT Press).

Cziko, Gary (2001) 'Heeding Darwin but Ignoring Bernard: External Behaviors are Not Selected’, Behavioral and Brain Sciences, 24(3), June, pp. 534-5.

Datta, Deepak K. (1991) 'Organizational Fit and Acquisition Performance', Strategic Management Journal, 12(4), pp. 281-97.

Darden, Lindley and Cain, A. J. (1989) 'Selection Type Theories', Philosophy of Science, 56, pp. 106-29.

Darwin, Charles R. (1859) On the Origin of Species by Means of Natural Selection, or the Preservation of Favoured Races in the Struggle for Life, first edn. (London: Murray).

Dawkins, Richard (1976) The Selfish Gene (Oxford: Oxford University Press).

Dawkins, Richard (1982) The Extended Phenotype: The Gene as the Unit of Selection (Oxford: Oxford University Press).

Dawkins, Richard (1983) 'Universal Darwinism', in D. S. Bendall (ed.) (1983) Evolution from Molecules to Man (Cambridge: Cambridge University Press), pp. 403-25.

Dennett, Daniel C. (1995) Darwin's Dangerous Idea: Evolution and the Meanings of Life (London: Allen Lane).

Depew, David J. and Weber, Bruce H. (1995) Darwinism Evolving: Systems Dynamics and the Genealogy of Natural Selection (Cambridge, MA: MIT Press).

Dewey, John (1922) Human Nature and Conduct: An Introduction to Social Psychology, 1st edn. (New York: Holt).

DiMaggio, Paul J. and Powell, Walter W. (1983) 'The Iron Cage Revisited: Institutional Isomorphism and Collective Rationality in Organizational Fields', American Sociological Review, 48(2), April, pp. 147-160.

Dosi, Giovanni, Nelson, Richard R. and Winter, Sidney G. (2000) 'Introduction: The Nature and Dynamics of Organizational Capabilities’ in Dosi, Giovanni, Nelson, Richard R. and Winter, Sidney G. (eds) (2000) The Nature and Dynamics of Organizational Capabilities (Oxford: Oxford University Press), pp. 1-22.

Durham, William H. (1991) Coevolution: Genes, Culture, and Human Diversity (Stanford: Stanford University Press).

Edelman, Gerald M. (1987) Neural Darwinism: The Theory of Neuronal Group Selection (New York: Basic Books).

Eigen, Manfred, Gardiner, William C., Schuster, Peter and Winkler-Oswatitsch, Ruthild (1981) 'The Origin of Genetic Information', Scientific American, 244(4), pp. 78-94. 
Eldredge, Niles (1985) Unfinished Synthesis: Biological Hierarchies and Modern Evolutionary Thought (Oxford: Oxford University Press).

Fisher, Ronald A. (1930) The Genetical Theory of Natural Selection (Oxford: Clarendon Press).

Frank, Steven A. (1998) Foundations of Social Evolution (Princeton: Princeton University Press).

Godfrey-Smith, Peter (2000) 'The Replicator in Retrospect', Biology and Philosophy, 15(3), June, pp. 403-23.

Hannan, Michael T. and Freeman, John (1984) 'Structural Inertia and Organizational Change’, American Sociological Review, 49(2), April, pp. 149-64.

Hannan, Michael T. and Freeman, John (1989) Organizational Ecology (Cambridge, MA: Harvard University Press).

Hayek, Friedrich A. (1988) The Fatal Conceit: The Errors of Socialism. The Collected Works of Friedrich August Hayek, Vol. I, ed. William W. Bartley III (London: Routledge).

Henrich, Joseph (2004) 'Cultural Group Selection, Coevolutionary Processes and Large-Scale Cooperation’, Journal of Economic Behavior and Organization, 53(1), pp. 3-35.

Henrich, Joseph and Boyd, Robert (2001) 'Why People Punish Defectors: Why Conformist Transmission Can Stabilize Costly Enforcement of Norms in Cooperative Dilemmas', Journal of Theoretical Biology, 208(1), pp. 79-89.

Hodgson, Geoffrey M. (1993) Economics and Evolution: Bringing Life Back Into Economics (Cambridge, UK and Ann Arbor, MI: Polity Press and University of Michigan Press).

Hodgson, Geoffrey M. (1998) 'Competence and Contract in the Theory of the Firm', Journal of Economic Behavior and Organization, 35(2), April, pp. 179-201.

Hodgson, Geoffrey M. (2001a) 'Is Social Evolution Lamarckian or Darwinian?' in Laurent, John and Nightingale, John (eds) (2001) Darwinism and Evolutionary Economics (Cheltenham: Edward Elgar), pp. 87-118.

Hodgson, Geoffrey M. (2001b) How Economics Forgot History: The Problem of Historical Specificity in Social Science (London and New York: Routledge).

Hodgson, Geoffrey M. (2002a) 'The Legal Nature of the Firm and the Myth of the FirmMarket Hybrid', International Journal of the Economics of Business, 9(1), February, pp. 37-60.

Hodgson, Geoffrey M. (2002b) 'Darwinism in Economics: From Analogy to Ontology', Journal of Evolutionary Economics, 12(2), June, pp. 259-81.

Hodgson, Geoffrey M. (2003a) 'John R. Commons and the Foundations of Institutional Economics’, Journal of Economic Issues, 37(3): 547-576.

Hodgson, Geoffrey M. (2003b) 'The Mystery of the Routine: The Darwinian Destiny of An Evolutionary Theory of Economic Change', Revue Economique, 54(2): 355-384.

Hodgson, Geoffrey M. (2004) The Evolution of Institutional Economics: Agency, Structure and Darwinism in American Institutionalism (London and New York: Routledge) in press. 
Hodgson, Geoffrey M. and Knudsen, Thorbjørn (2003) 'Firm-Specific Learning and the Nature of the Firm: Why Transaction Cost Theory May Provide an Incomplete Explanation', University of Hertfordshire, unpublished mimeo.

Hofbauer, Josef and Sigmund, Karl (1998) Evolutionary Games and Population Dynamics (Cambridge: Cambridge University Press).

Hull, David L. (1973) Darwin and His Critics: The Reception of Darwin's Theory of Evolution by the Scientific Community (Cambridge, MA: Harvard University Press).

Hull, David L. (1980) 'Individuality and Selection', Annual Review of Ecology and Systematics, 11, pp. 311-32.

Hull, David L. (1981) 'Units of Evolution: A Metaphysical Essay', in Jensen, U. L. and Harré, Rom (1981) The Philosophy of Evolution (Brighton: Harvester Press), pp. 23-44.

Hull, David L. (1988) Science as a Process: An Evolutionary Account of the Social and Conceptual Development of Science (Chicago: University of Chicago Press).

Hull, David L. (2001) Science and Selection. Essays on Biological Evolution and the Philosophy of Science (Cambridge: Cambridge University Press).

Hull, David L., Langman, Rodney E., and Glenn, Sigrid S. (2001) 'A General Account of Selection: Biology, Immunology and Behavior’, Behavioral and Brain Sciences, 24(3), June, pp. 511-28.

James, William (1880) 'Great Men, Great Thoughts, and the Environment', Atlantic Monthly, 46, pp. 441-59. Reprinted in James, William (1897) The Will to Believe and Other Essays in Popular Philosophy (New York and London: Longmans Green), pp. 216-54.

James, William (1890) The Principles of Psychology, 1st edn. (New York: Holt).

Keller, Laurent (ed.) (1999) Levels of Selection in Evolution (Princeton: Princeton University Press).

Kerr, Benjamin and Godfrey-Smith, Peter (2002a) 'Individualist and Multi-Level Perspectives in Structured Populations’, Biology and Philosophy, 17(4), September, pp. 477-517.

Kerr, Benjamin and Godfrey-Smith, Peter (2002b) 'On Price’s Equation and Average Fitness’, Biology and Philosophy, 17(4), September, pp. 551-65.

Knudsen, Thorbjørn (2001) 'Nesting Lamarckism within Darwinian Explanations: Necessity in Economics and Possibility in Biology?', in Laurent, John and Nightingale, John (eds) (2001) Darwinism and Evolutionary Economics (Cheltenham: Edward Elgar), pp. 121-59.

Knudsen, Thorbjørn (2002a) 'The Significance of Tacit Knowledge in the Evolution of Human Language’, Selection, 3(1), pp. 93-112.

Knudsen, Thorbjørn (2002b) 'Economic Selection Theory', Journal of Evolutionary Economics, 12(4), October, pp. 443-70.

Knudsen, Thorbjørn (2004): "General Selection Theory and Economic Evolution. The Price Equation and the Genotype/Phenotype Distinction" Journal of Economic Methodology (forthcoming).

Kusewitt, J. B. (1985) 'An Exploratory Study of Strategic Acquisition Factors Relating to Performance’, Strategic Management Journal, 6(2), pp. 151-169. 
Langlois, Richard N. and Robertson, Paul L. (1995) Firms, Markets and Economic Change: A Dynamic Theory of Business Institutions (London and New York: Routledge).

Lazaric, Nathalie (2000) 'The Role of Routines, Rules and Habits in Collective Learning: Some Epistemological and Ontological Considerations', European Journal of Economic and Social Systems, 14(2), pp. 157-71.

Lazaric, Nathalie and Denis, Blandine (2001) 'How and Why Routines Change: Some Lessons from the Articulation of Knowledge with ISO 9002 Implementation in the Food Industry', Économies et Sociétés, Série Dynamique technoloqique et organisation, 6(4), pp. 585-611.

Levitt, Barbara and March, James G. (1988) 'Organizational Learning', Annual Review of Sociology, 14, pp. 319-40.

Lewontin, Richard C. (1970) 'The Units of Selection', Annual Review of Ecology and Systematics, 1, pp. 1-18.

Lynch, Aaron (1996) Thought Contagion: How Beliefs Spread Through Society (New York: Basic Books).

Margolis, Howard (1994) Paradigms and Barriers: How Habits of Mind Govern Scientific Beliefs (Chicago: University of Chicago Press).

Maynard Smith, John and Szathmáry, Eors (1995) The Major Transitions in Evolution (Oxford: WH Freeman Press).

Maynard Smith, John and Szathmáry, Eors (1999) The Origins of Life: From the Birth of Life to the Origin of Language (Oxford: Oxford University Press).

Mayr, Ernst (1982) The Growth of Biological Thought: Diversity, Evolution, and Inheritance (Cambridge, MA: Harvard University Press).

Metcalfe, J. Stanley (1998) Evolutionary Economics and Creative Destruction (London: Routledge).

Miller, Danny (1994) 'What Happens After Success: The Perils of Excellence', Journal of Management Studies, 31(3), pp. 325-58.

Miner, Anne S. (1994) 'Seeking Adaptive Advantage: Evolutionary Theory and Managerial Action', in Baum, Joel A.C. \& Singh, Jitendra V. (eds.) (1994) Evolutionary Dynamics of Organizations (New York and Oxford: Oxford University Press), pp. 76-89.

Murphy, James Bernard (1994) 'The Kinds of Order in Society', in Mirowski, Philip (ed.) (1994) Natural Images in Economic Thought: Markets Read in Tooth and Claw (Cambridge and New York: Cambridge University Press), pp. 536-82.

Nanay, Bence (2002) 'The Return of the Replicator: What is Philosophically Significant in a General Account of Replication and Selection', Biology and Philosophy, 17(1), January, pp. 109-21.

Nelson, Richard R. (1991) 'Why Do Firms Differ, and How Does it Matter?', Strategic Management Journal, 12, Special Issue, Winter, pp. 61-74.

Nelson, Richard R. (1995) 'Recent Evolutionary Theorizing About Economic Change', Journal of Economic Literature, 33(1), March, pp. 48-90.

Nelson, Richard R. and Winter, Sidney G. (1982) An Evolutionary Theory of Economic Change (Cambridge, MA: Harvard University Press). 
Nelson, Richard R. and Winter, Sidney G. (2002) 'Evolutionary Theorizing in Economics', Journal of Economic Perspectives, 16(2), Spring, pp. 23-46.

Peirce, Charles Sanders (1992) Reasoning and the Logic of Things: The Cambridge Conferences Lectures of 1898, introduced by Kenneth L. Ketner and Hilary Putnam (Cambridge, MA: Harvard University Press).

Plotkin, Henry C. (1994) Darwin Machines and the Nature of Knowledge: Concerning Adaptations, Instinct and the Evolution of Intelligence (Harmondsworth: Penguin).

Polanyi, Michael (1967) The Tacit Dimension (London: Routledge and Kegan Paul).

Popper, Karl R. (1972) Objective Knowledge: An Evolutionary Approach (Oxford: Oxford University Press).

Price, George R. (1970) 'Selection and Covariance’, Nature, 227, pp. 520-1.

Price, George R. (1972) 'Extensions of Covariance Selection Mathematics', Annals of Human Genetics, 35, pp. 485-90.

Price, George R. (1995) 'The Nature of Selection', Journal of Theoretical Biology, 175, pp. 389-96.

Reber, Arthur S. (1993) Implicit Learning and Tacit Knowledge: An Essay on the Cognitive Unconscious (Oxford and New York: Oxford University Press).

Rogers, Everett M. (1995) Diffusion of Innovations, 3rd edn. (New York: Free Press).

Ritchie, David G. (1896) 'Social Evolution', International Journal of Ethics, 6(2), pp. 165-81. Reprinted in Ritchie, David G. (1998) The Collected Works of D. G. Ritchie, ed. and introduced by Peter P. Nicholson (Bristol: Thoemmes), vol. 4.

Ryle, Gilbert (1949) The Concept of Mind (New York: Barnes and Noble).

Simon, Herbert A. (1990) 'A Mechanism for Social Selection and Successful Altruism', Science, 250, 21 December, pp. 1665-8.

Sober, Elliott (1984) The Nature of Selection: Evolutionary Theory in Philosophical Focus (Cambridge, MA; MIT Press).

Sober, Elliott and Wilson, David Sloan (1998) Unto Others: The Evolution and Psychology of Unselfish Behavior (Cambridge, MA: Harvard University Press).

Soderquist, Larry D. (2000) 'Theory of the Firm: What a Corporation Is', Journal of Corporation Law, 25(2), Winter, pp. 375-81.

Sperber, Dan (2000) 'An Objection to the Memetic Approach to Culture', in Aunger, Robert (ed.) (2000) Darwinizing Culture: The Status of Memetics as a Science (Oxford and New York: Oxford University Press), pp. 162-73.

Stinchcombe, Arthur L. (1990) Information and Organizations (Berkeley: University of California Press).

Szulanski, Gabriel (1996) 'Exploring Internal Stickiness: Impediments to the Transfer of Best Practice Within the Firm’, Strategic Management Journal, 17, Winter Special Issue, pp. 27-43.

Szulanski, Gabriel (2000) 'Appriopriability and the Challenge of Scope: Banc One Routinizes Replication’, in Dosi, Giovanni, Nelson, Richard R. and Winter, Sidney G. (eds) (2000) 
The Nature and Dynamics of Organizational Capabilities (Oxford: Oxford University Press), pp. 69-98.

Tomasello, Michael (2000) The Cultural Origins of Human Cognition (Cambridge, MA: Harvard University Press).

Veblen, Thorstein B. (1899) The Theory of the Leisure Class: An Economic Study in the Evolution of Institutions (New York: Macmillan).

Veblen, Thorstein B. (1919) The Place of Science in Modern Civilisation and Other Essays (New York: Huebsch).

Walter, Gordon (1991) 'Culture Collisions in Mergers and Acquisitions’, in Frost, Peter J., Moore, Larry R., Reis, Meryl, Lundberg, Craig D. and Martin, Joanne (eds) (1991) Reframing Corporate Culture (San Francisco: Sage), pp. 301-14.

Williams, George C. (1966) Adaptation and Natural Selection (Princeton, NJ; Princeton University Press).

Winter, Sidney G., Jr (1971) 'Satisficing, Selection and the Innovating Remnant', Quarterly Journal of Economics, 85(2), May, pp. 237-61.

Winter, Sidney G., Jr (1987) 'Natural Selection and Evolution’, in Eatwell, John, Milgate, Murray and Newman, Peter (eds) (1987) The New Palgrave Dictionary of Economics (London: Macmillan), vol. 3, pp. 614-7.

Winter, Sidney G., Jr (1990) 'Survival, Selection, and Inheritance in Evolutionary Theories of Organization', in Singh, Jitendra V. (ed.) (1990) Organizational Evolution: New Directions (London: Sage), pp. 269-97.

Winter, Sidney G. Jr (1995) 'Four Rs of Profitability: Rents, Resources, Routines, and Replication' in Montgomery, Cynthia A. (ed.) (1995) Resource-Based and Evolutionary Theories of the Firm: Towards a Synthesis (Boston: Kluwer), pp. 147-78.

Winter, Sidney G., Jr (1988) 'On Coase, Competence, and the Corporation', Journal of Law, Economics, and Organization, 4(1), Spring, pp. 163-80.

Zucker, Lynne G. (1987) 'Institutional Theories of Organization', Annual Review of Sociology, 13, pp. 443-64. 